\title{
The Potential for Urban Vegetation to Mitigate Ambient Air Pollution Threats to Public Health
}

\author{
By Sonak Patel
}

\begin{abstract}
This paper assesses the threat that ambient air pollution poses to urban public health and the potential role of urban vegetation to mitigate those threats. Air pollution is a major global risk to health, especially in urban areas. In this paper, four major air pollutants were assessed: particulate matter, tropospheric ozone, nitrogen dioxide, and sulfur dioxide. These pollutants were found to have several adverse effects, including increasing mortality and respiratory morbidity. These pollutants come from a variety of sources, but a major contributor in urban areas is the burning of fossil fuels in automobiles. The adverse health effects of pollution are expected to grow as climate change worsens air quality. Research and case studies find that urban vegetation can filter air and remove pollutants through deposition and stomatal uptake. The effectiveness of air pollution removal is dependent upon specific variables, including leaf characteristics, type of vegetation, and seasons. Urban vegetation may worsen air quality in some cases due to slowing ventilation and producing biological volatile organic compounds. While urban vegetation has potential to mitigate ambient air pollution, conducting site specific research is needed when implementing greenspace policies.
\end{abstract}

\section{Introduction}

Air pollution represents the most significant environmental risk to health (World Health Organization [WHO], 2016). Globally, approximately $90 \%$ of the population lives in a region that does not achieve $\mathrm{WHO}$ air quality guidelines. Ambient air pollution is estimated to lead to the death of over 3 million people annually (WHO, 2016). Despite a decreasing death rate per capita, there has been an estimated increase in annual deaths from exposure to outdoor air pollution, rising from 3.39 million in 1990 to 4.23 million in 2016 (Ritchie \& Roser, 2017). The threat of air pollution is more significant in urban areas because they concentrate emission sources, like automobiles, and, consequently, have poor air quality (Strosnider, Kennedy, Monti, \& Yip, 2017; Xing, Xu, Shi, \& Lian, 2015). As the current global trend of urbanisation continues and cities grow, more people will be exposed to poor air quality and face negative health impacts. Climate change is also projected to decrease air quality in the future (Jacob \& Winner, 2009).

As climate change and urbanisation magnify the negative health implications of air pollution, municipalities must explore options for mitigating air pollution. One potential method of reducing air pollution is through the use of urban greenspace. Trees and other vegetation have a demonstrated capacity to filter air and reduce the number of air pollutants (Zupancic, Westmacott, \& Bulthuis, 2015). However, vegetation can also exacerbate air pollution by reducing airflow and producing biologically volatile organic compounds.

This paper explores the sources and negative health impacts of ambient air pollution and the potential for urban vegetation to improve air quality. Four air pollutants were assessed: 
particulate matter, tropospheric ozone, nitrogen dioxide, and sulfur dioxide. The benefits of greenspace in improving air quality are explored through a number of case studies. This paper also explores variables that affect the effectiveness of urban greenspace in improving air quality.

\section{Air Pollution, Sources and Health Effects}

The composition of air varies according to location, dependent on local sources and climatic conditions. Particulate matter, tropospheric ozone, nitrogen dioxide, and sulfur dioxide are identified as common air pollutants in North America with significant adverse health effects. Table 1 summarizes the sources and health effects of each air pollutant.

\section{Particulate Matter}

Particulate matter refers to a variety of solid and liquid particles suspended in air (WHO, 2016). Particulates vary by region and sources, but common ones include sulfates, nitrates, ammonium, sodium, potassium, calcium, magnesium, carbons, metals, and biological products (WHO, 2013). Particulate matter can be characterised by the size of the particles, expressed in micrometers. Coarse particulate matter $\left(P M_{10}\right)$ refers to particulates with an aerodynamic diameter between 2.5 and 10 micrometres. Fine particulate matter $\left(\mathrm{PM}_{2.5}\right)$ refers to particulates with an aerodynamic diameter less than 2.5 micrometres (WHO, 2013). Particulate matter can be further characterised by the location of the formation. Primary particles are emitted directly into the air, whereas secondary source air particles are formed in the air by the reaction of compounds, including nitrogen oxides and sulfur oxides (WHO, 2013).

\section{Sources of Particulate Matter}

Anthropogenic sources of particulate matter include fossil fuel combustion, non-exhaust traffic emissions such as the abrasion of tires and pavement, construction and demolition, and agricultural activities that produce ammonium.
(WHO, 2013; Bari, MacNeill, Kindzierski, Wallace, Herox, \& Wheeler, 2014). A study by Bari \& Kindzierski (2017) found local traffic to be an important contributor to fine particulate matter in Edmonton, Canada, along with other major secondary organic aerosol, secondary inorganic aerosol, and biomass burning. The background regional sulphate concentrations in Alberta are higher than other provinces, which may be apportioned to oil and gas extraction and production activities (Bari \& Kindzierski, 2017). Natural sources of particulate matter include windblown dust, salts, forest fires, and plant debris (European Environmental Agency, 2012).

\section{Adverse Health Effects}

Particulate matter is small enough to penetrate the thoracic cavity, causing significant harm to the respiratory system (WHO, 2013; Richie \& Roser, 2017). $P_{2.5}$ is capable of penetrating further into the lungs, interfering with lung function (Xing et al., 2015). Elevated $P M_{2.5}$ concentrations were correlated with increased levels of mortality and morbidity (Xing et al., 2015; Tiwary et al., 2009). Exposure to coarse particulate matter has been found to cause alveolar inflammation and an increased risk of respiratory infections, including pneumonia (Tiwary et al., 2009). A US study found that a reduction of $10 \mu \mathrm{g} /$ $\mathrm{m}^{3}$ of $\mathrm{PM}_{2.5}$ would increase average lifespan by 0.35 years (Xing et al., 2015). For every increase of $100 \mu \mathrm{g} / \mathrm{m}^{3}$ of $\mathrm{PM}_{2.5}$, morbidity was found to increase by $12 \%$ (Xing et al., 2015). A separate study found that the mortality of lung cancer increased by $15-27 \%$ with a $10 \mu \mathrm{g} /$ $\mathrm{m}^{3}$ increase of particulate matter (Xing et al., 2015). Approximately $3 \%$ of cardiopulmonary and $5 \%$ of lung cancer deaths are estimated to be due to particulate matter exposure (WHO, 2013). Exposure to particulate matter has also been linked to irregular heartbeat, decreased lung function, and irritation of airways, causing coughing and difficulty breathing (EPA, 2017a).

Particulate matter presents a greater risk to the elderly, the young, and those with preexisting lung or heart conditions (EPA, 2017a). Exposure to particulate matter can hinder lung 
development in children, reducing lung function (WHO, 2013). Long-term exposure to coarse particles has been correlated with diminished cognitive function in older women (Weuve et al., 2012). $P_{2.5}$ is also associated with preterm birth and low birth weights (Zupancic et al., 2015).

\section{Ground-Level Ozone}

Ozone is a molecule containing three atoms of oxygen and can be categorized in two ways, depending on where in the atmosphere it is located. Stratospheric ozone, known as the "ozone layer", plays a crucial role protecting the Earth from harmful ultraviolet radiation produced by the sun. The ozone layer is located in the upper atmosphere. The other form of ozone is tropospheric ozone, which locates at ground level. Tropospheric ozone is a product of chemical reactions and has significant negative health effects (EPA, 2017b).

\section{Sources of Ground-Level Ozone}

Ground-level ozone is produced when nitrogen oxides and volatile organic compounds (VOCs) react in sunlight (Liu et al., 2017). Precursors for determining the rate of ozone formation are the ratio of nitrogen oxides and $V O C s$, where nitrogen oxide limiting reactions produce ground-level ozone (Simon, Reff, Wells, Xing \& Frank, 2015). Ozone producing reactions require sunlight and are dependent on factors like cloud cover and sunlight penetration (West Michigan Clean Air Coalition, 2017). A positive correlation between temperature and ozone formation has been determined, as warmer temperatures lead to faster reaction rates (Doherty et al., 2013). Because of more daylight and higher temperatures, ozone production peaks in spring and summer (Doherty et al., 2013). Nitrogen dioxide and VOCs, precursors for ozone formation, are products of fossil fuel combustion and are increasing due to automobile usage and industrial activities.

\section{Adverse Health Effects}

Ground-level ozone has been found to cause adverse health effects in both active and asthmatic individuals (WHO, 2005). Biologically, the inhalation of ozone causes airway inflammation and reduces pulmonary function (Jerrett et al., 2009). Exposure to ozone has been found to increase the incidence and mortality of respiratory illnesses (Liu et al., 2017; Berman et al., 2012). Increased mortality results from ozone reducing lung function, placing individuals at greater risk of death from respiratory-related illnesses and increasing risk for individuals with existing respiratory ailments (Jerrett et al., 2009). A WHO (2005) report found that an eight hour concentration of $160 \mu \mathrm{g} / \mathrm{m}^{3}$ of ozone was associated with an estimated $3-5 \%$ increase in daily mortality. The study by Jerrett et al. (2009) found that, controlling for the effects of fine particulate matter, ozone significantly increased the risk of dying from respiratory causes. For every $10 \mathrm{ppb}$ increase in ozone exposure, the risk of death from respiratory causes rose by $2.9 \%$ in single-pollutant models (Jerrett et al., 2009). Tropospheric ozone is also correlated with creating and exacerbating asthmatic conditions (Jerrett et al., 2009; Berman et al., 2012) as well as heart attacks and cardiovascular problems (Weinhold, 2008). Individuals with existing chronic lung and cardiovascular disease are more at risk from ground-level ozone than others (Berman et al., 2012). Ground level ozone was also found to present an increased risk of respiratory morbidity in children (WHO, 2005).

\section{Nitrogen Dioxide}

Nitrogen dioxide is a toxic gas (WHO, 2005) that reacts in the atmosphere to produce secondary air pollutants. In the presence of hydrocarbons and ultraviolet light, nitrogen dioxide reacts to form ozone and nitrate aerosols, creating fine particulate matter (WHO, 2003).

\section{Sources of Nitrogen Dioxide}

Nitrogen dioxide is a product of the reaction between nitrogen and oxygen in the combustion of fossil fuels (Jarvis, Adamkiewicz, Heroux, Rapp \& Kelly, 2010). The largest anthropogenic source 
of nitrogen dioxide is automobile emissions (Jarvis et al., 2010). Individuals living near arterial or high traffic roadways can be exposed to greater concentrations of nitrogen dioxide (EPA, 2011).

\section{Adverse Health Effects}

Short-term exposure to nitrogen dioxide can cause airway inflammation and aggravate respiratory ailments, including coughing, wheezing, and difficulty breathing (EPA, 2017c). Over time, exposure to nitrogen dioxide can induce asthma and place individuals at greater risk of respiratory morbidity (EPA, 2017c and WHO, 2003). Studies have also shown a correlation between rising nitrogen dioxide concentrations and increased mortality (WHO, 2003). Children, the elderly, and those with asthma are at greater risk from nitrogen dioxide (EPA, 2017c). Exposure to nitrogen dioxide has been found to be correlated with reduced lung function in children (WHO, 2005). Because nitrogen dioxide produces other air pollutants, it is difficult to isolate the effect of nitrogen dioxide, controlling for other pollutants (WHO, 2003). However, nitrogen dioxide remains a dangerous pollutant because it can lead to the production of ground-level ozone and particulate matter, which have demonstrated significant negative health impacts.

\section{Sulfur Dioxide}

Sources of Sulfur Dioxide

Sulfur dioxide is produced by burning fossil fuels, especially coal, therefore the primary producers are fossil fuel power plants and industrial processes that use fossil fuels, (Chen et al., 2012). Other producers include ore extraction industrial processes and heavy vehicles and equipment. In nature, sulfur dioxide is produced by volcanoes (EPA, 2017d).

\section{Adverse Health Effects}

Exposure to sulfur dioxide causes respiratory irritation (EPA, 2017d) and there is evidence of an association between sulfur dioxide exposure and cardiovascular and respiratory mortality (Chen et al., 2012). A study in 12 Canadian cities found a significant correlation between long-term exposure to sulfur dioxide and mortality rates (WHO, 2005). Additionally, sulfur dioxide is associated with pre-term births (Zupancic et al., 2015). sulfur dioxide also reacts in the atmosphere to produce particulate matter (EPA, 2017d). Children, the elderly, and those with asthma are at greater risk from nitrogen dioxide (EPA, 2017c). Exposure to nitrogen dioxide has been found to be correlated with reduced lung function in children (WHO, 2005). Because nitrogen dioxide produces other air pollutants, it is difficult to isolate the effect of nitrogen dioxide, controlling for other pollutants (WHO, 2003). However, nitrogen dioxide remains a dangerous pollutant because it can lead to the production of ground-level ozone and particulate matter, which have demonstrated significant negative health impacts.

\section{Climate Change}

The threat of air pollution is expected to be aggravated by climate change affecting meteorological conditions (Jacob \& Winner, 2009). This is primarily due to two effects: the warming of the earth and increased frequency of stagnation periods.

Climate change is projected to lead to significant warming across the planet. As temperatures rise, the concentration of groundlevel ozone is also projected to increase in regions with high nitrogen oxide concentrations as hotter temperatures contribute to a faster rate of reaction (Doherty et al., 2013; Jacob \& Winner, 2009). Climate change will also change precipitation patterns (Jacob \& Winner, 2009). Greater precipitation is negatively associated with ozone production (Jacob \& Winner, 2009). As some areas become drier and receive less precipitation, the levels of ambient ground-level ozone will increase.

Climate change would also result in greater periods of stagnation, which would result in decreased air quality by decreasing the rate of pollutant dispersion. Changes in ventilation would 
Table 1: Summary of Health Effects of Air Pollutants

\begin{tabular}{|c|c|c|c|}
\hline Pollutants & Sources & Adverse Health Effects & Sources \\
\hline Particulate Matter & $\begin{array}{l}\text { - Fossil fuel combustion } \\
\text { - Non exhaust traffic } \\
\text { emissions } \\
\text { - Industrial activity } \\
\text { - Agricultural activity }\end{array}$ & $\begin{array}{l}\text { - Increased respiratory and } \\
\text { - } \text { Respirdiovascular mortality } \\
\text { (asthma, bronchitis, etc.) } \\
\text { - Increase susceptibility to } \\
\text { respiratory infections } \\
\text { - Increased chance of } \\
\text { - developing lung cancer } \\
\text { - Irregular heartbeat } \\
\text { - Decreased lung function } \\
\text { - Lung development in } \\
\text { children hindered } \\
\text { - Preterm birth and low birth } \\
\text { weights }\end{array}$ & $\begin{array}{l}\text { - Xing et al., } 2015 \\
\text { - Tiwary et al., } \\
2009 \\
\text { - } \mathrm{WHO}, 2013 \\
\text { - EPA, 2017a } \\
\text { - Zupancic et al., } \\
2015\end{array}$ \\
\hline $\begin{array}{l}\text { Tropospheric } \\
\text { Ozone }\end{array}$ & $\begin{array}{l}\text { - Formed in the } \\
\text { reaction between } \\
\text { nitrogen oxides and } \\
\text { volatile organic } \\
\text { compounds in } \\
\text { sunlight }\end{array}$ & $\begin{array}{l}\text { - Airway inflammation } \\
\text { - Reduced pulmonary function } \\
\text { - Increased mortality } \\
\text { - Induce and exacerbate } \\
\text { asthmatic conditions } \\
\text { - Heart attacks and } \\
\text { cardiovascular ailments }\end{array}$ & $\begin{array}{l}\text { - Jerrett et al, } 2009 \\
\text { - Berman et al, } \\
2012 \\
\text { - Weinhold, } 2008\end{array}$ \\
\hline Nitrogen Dioxide & $\begin{array}{l}\text { - Produced by fossil } \\
\text { fuel emissions } \\
\text { - Primary source is } \\
\text { automobile emissions }\end{array}$ & $\begin{array}{l}\text { - Airway inflammation } \\
\text { - Induce asthma }\end{array}$ & $\begin{array}{l}\text { - } \mathrm{EPA}, 2017 \mathrm{c} \\
\text { - } \mathrm{WHO}, 2003\end{array}$ \\
\hline Sulfur Dioxide & $\begin{array}{l}\text { - Primary source is } \\
\text { automobile emissions }\end{array}$ & $\begin{array}{l}\text { - Respiratory irritation } \\
\text { - Preterm birth }\end{array}$ & $\begin{array}{l}\text { - EPA, 2017d } \\
\text { - Zupancic et al., } \\
2015\end{array}$ \\
\hline
\end{tabular}

have a significant effect on increasing particulate matter concentration (Jacob \& Winner, 2009).

Models have found that the effect of climate change will be most strongly felt by urban centres (Jacob \& Winner, 2009). Air pollution risks will increase as climate change effects increase in frequency and magnitude.

\section{Urban Greenspace as a Response to Air Pollution}

A potential method of mitigating ambient air pollution is through urban greenspaces. Vegetation has a natural ability to filter pollutants, including particulate matter, tropospheric ozone, nitrogen dioxide, and sulfur dioxide (Zupancic et al., 2015). A literature review done by the David Suzuki Foundation (Zupancic et al., 2015) identified that $92 \%$ of applicable studies reported pollution mitigating effects of urban greenspace.

There are two ways for vegetation to reduce the concentration of air pollutants: through deposition on plant surfaces, including leaves and bark, and stomatal uptake (Grote et al., 2016 and Selmi et al., 2016). Deposition rates are dependent on air movement, transfer through boundary layer adjacent to the plant surface, 
and the absorption capacity of surfaces (Grote et al., 2016). The uptake of pollutants occurs by the stomata, which are pores on the leaf surface that open and close to regulate fluids in the leaf (Grote et al., 2016). Uptake rates remain high for pollutants that are immediately metabolised, such as ozone and nitrogen dioxide.

A study done in Sydney, Australia found that, accounting for traffic conditions, sites with greater concentrations of greenspace had lower concentrations of particulate matter (Irga, Burchett, \& Torpy, 2015). This result aligns with the findings of a study modelling changes in coarse particulate matter in London, finding that a greenspace of 100 square kilometres containing $70 \%$ grassland, $20 \%$ sycamore maple, and 5\% Douglas fir would result in a coarse particulate matter reduction of 90.41 tonnes per year, or 0.009 tonnes per hectare per year (Tiwary et al., 2009). Using a health income model, this coarse particulate matter reduction would result in the prevention of 2 premature deaths and 2 hospital admissions for respiratory ailments (Tiwary et al., 2009).

A study done in Strasbourg, France showed similar findings. The model used found that 2,171 hectares of greenspace removed 88.23 tons of air pollutants per year (Selmi et al., 2016). Of these, 13.84 tons were nitrogen dioxide, 55.88 tons were ozone, 1.04 tons were sulfur dioxide, 11.77 tons were coarse particulate matter, and 4.51 tons were fine particulate matter. In this case, urban vegetation removed $0.5 \%$ of emitted nitrogen dioxide, $0.5 \%$ of emitted sulfur dioxide, $6.6 \%$ of emitted coarse particulate matter, and $1.5 \%$ of fine particulate matter (Selmi et al., 2016). A study in Barcelona found the urban forest removed 166 tons of PM10, 54.6 tons of nitrogen dioxide, and 73.6 tonnes of tropospheric ozone (Zupancic et al., 2015).

An analysis of ten US cities found that the total removal of fine particulate matter by trees ranged from 4.7 tonnes in Syracuse to 64.5 tonnes in Atlanta, with the highest net removal rate of 0.36 grams per square metre per year (Nowak, Hirabayashi, Bodine, \& Hoehn, 2013). This reduction in particulate matter was projected to result in mortality reductions as high as 7.6 people per year (Nowak et al., 2013). The study also calculated health benefits as a monetary value, with the average value per hectare of tree cover being $\$ 1,600$, with a peak of $\$ 3,800$ in New York (Nowak et al., 2013).

\section{Relevant Characteristics}

There are a number of characteristics that will impact the degree of effectiveness of vegetation in the mitigating air pollution. In a literature review produced by the David Suzuki Foundation, the most relevant characteristics that affect the relationship between greenspace and air quality were greenspace density and leaf characteristics (Zupancic et al., 2015). Increased density, measured as crown cover or leaf area density, is associated with greater mitigation of air pollution (Zupancic et al., 2015). Leaf characteristics also affect the rate of deposition. The presence of waxes and hairs has a significant effect, with waxy leaves being found to almost double the rate of particulate matter deposition (Grote et al., 2016; Tiwary et al., 2009). Wet leaves also have higher deposition rates, thus higher precipitation levels are correlated with greater particulate removal rates from urban vegetation (Zupancic et al., 2015). Pine species are found to be efficient at reducing particulate matter concentrations (Zupancic et al., 2015).

Because air pollution filtration improves with leaf area, the pollution removal impacts are greater in spring and summer seasons, inleaf season (Selmi et al., 2016; Zupancic et al., 2015). Thus, the effectiveness of urban trees in air pollution mitigation may be limited in northern climates with longer winters (Zupancic et al., 2015). Leaf area additionally accounts for why larger trees are more effective than small trees at air pollution removal (Selmi et al., 2016).

There are also a variety of greenspaces explored in the report produced by the David Suzuki Foundation, including green buildings. Green buildings are defined as structures containing a vegetated wall or roof. Green buildings were found to have a significant effect on air pollution mitigation, as evidenced by a study of eight green roof experiments finding 
that the average nitrogen dioxide concentration was reduced by $49 \%$ (Zupancic et al., 2015).

\section{Negative Effects of Urban Greenspace}

There is some evidence that vegetation emits biological volatile organic compounds which, given a sufficient concentration of nitrogen dioxide, can produce tropospheric ozone (Zupancic et al., 2015). The production of biological volatile organic compounds (BVOCs) varies by species, and in areas where nitrogen dioxide concentrations are high, municipalities should plant low emitting species such as sugar maple (Zupancic et al., 2015). However, most studies have found the air quality improvements outweigh the negative effect of BVOC emissions (Zupancic et al., 2015).

There is a potential for negative effects for urban trees in street canyons due to the reduced air circulation (Zupancic et al., 2015). Street canyons are defined as areas where a street is surrounded by tall buildings. Ventilation is responsible for dispersing air pollution, and if trees limit the airflow in the area, the aerodynamic effect can outweigh the pollution removal of the trees and lead to high concentrations of air pollutants in the street canyon that threaten the health of users of that space (Zupancic et al., 2015). Trees with dense canopies should be avoided in street canyons (Shaneyfelt, Anderson, Kumar, \& Hunt, 2017). Other forms of urban vegetation may be more useful to address in canyon air pollution, such as green walls (Zupancic et al., 2015). A study using a model to replicate a street canyon found that implementing green walls resulted in a reduction of $40 \%$ concentration of nitrogen dioxide and $60 \%$ concentration of coarse particulate matter under optimal conditions (Pugh et al., 2012). Locating street trees further apart may also increase the effectiveness of trees in urban canyons (Shaneyfelt et al., 2017).

\section{Limitations}

This paper explores the potential benefits, considerations, and negatives of urban greenspace. However, air quality conditions and the potential for urban vegetation to improve air quality is locally specific and thus it is difficult to provide specific guidelines for local implementation. This also leads to disagreements in the literature over the effectiveness of vegetation in air pollution removal. For example, a winter city may have reduced benefits from greenspace due to longer winters and climate conditions may limit the species that could be grown. Additionally, within the city, street conditions like canyons and traffic volume will affect the effectiveness of greenspace. Therefore, assessing the mitigation potential of greenspace for a given area requires site-specific research.

\section{Conclusions}

Air pollution is a significant threat to public health and air quality is projected to fall due to urbanisation and climate change. Already, $90 \%$ of the world's population lives in a region that fails to meet $\mathrm{WHO}$ air quality guidelines (WHO, 2016). It is becoming increasingly important that municipalities develop methods to mitigate the threat of air pollution.

The negative health effects of four major air pollutants were explored in this paper. Individually and together, these air pollutants have significant negative effects, including increased mortality, increased respiratory morbidity, airway inflammation and coughing, wheezing, bronchitis, increased risk of developing lung cancer, inducing and exacerbating asthmatic conditions, development ailments for children, and pregnancy ailments.

A potential mitigation tool is through the use of urban vegetation. Models and case studies demonstrate pollutant filtering through deposition and stomatal uptake. There are a variety of variables related to the effectiveness of urban greenspace in mitigating pollution efforts, including leaf density area, seasonal factors, and species unique factors like leaf characteristics. However, there are negative factors that must also be considered; trees reduce ventilation and airflow and plants produce biological volatile organic compounds that may have negative air quality effects. 
While there are demonstrated air pollution reduction benefits associated with urban greenspace, the average reduction is not significant enough to completely prevent air pollution health risks. However, the benefits of urban trees come from the relatively cheap cost relative to other mitigation methods and the benefits urban greenspace provides in other aspects. Urban greenspace has benefits in cooling areas (Zupancic et al., 2015) and provide habitats that support biodiversity. Urban parks provide spaces for socialisation and recreation and have psychological benefits for communities. These benefits, in addition to the air pollutant reduction value, provide a compelling case for the inclusion of more trees and policies that support street trees, park spaces, shrubs and hedges, green roofs, green walls, and other ways to introduce vegetation to the built landscape. Site-specific studies must be completed to determine the benefits of locating vegetation in a given area and avoid negative effects of urban vegetation. Greenspace should not be used to replace other air quality improvement initiatives, but rather be considered one of many tools to improve air quality. Demand-side changes, such as reducing fossil fuel consumption and automobile use, and other mitigation methods must also be implemented to improve air quality. However, urban vegetation is an effective tool to mitigate the risk of air pollution to urban health.

\section{Note}

$\mu \mathrm{g} / \mathrm{m}^{3}$, or microgram per cubic meter, is a unit of measurement for the concentration of air pollutants (European Environment Agency, n.d.).

\section{References}

Bari, M. A., \& Kindzierski, W.B. (2017).

Concentrations, sources and human health risk of inhalation exposure to air toxics in Edmonton, Canada. Chemosphere, 173, 160-171. https://doi.org/10.1016/i. chemosphere.2016.12.157

Bari, M. D., MacNeill, M., Kindzierski W.B., Wallace, L., Herox, M.E., \&
Wheeler, A.J. (2014). Predictors of coarse particulate matter and associated endotoxin concentrations in residential environments. Atmospheric Environment, 92, 221-230. https://doi.org/10.1016/i. atmosenv.2014.04.025

Berman, J. D., Fann, N., Hollingsworth, J. W., Pinkerton, K. E., Rom, W. N., Szema, A. M., Breysse, P. N., White, R. H., Curriero, F. C. (2012). Health benefits from largescale ozone reduction in the United States. Environmental Health Perspectives, 120(10), 1404-1410. https://doi.org/10.1289/ ehp.1104851

Chen, R., Huang, W., Wong, C., Wang, Z., Thach, T., Chen, B., Kan, H. (2012). Shortterm exposure to sulfur dioxide and daily mortality in 17 Chinese cities: the China air pollution and health effects study (CAPES). Environmental Research, 118, 101 - 106. https://doi.org/10.1016/i. envres.2012.07.003

Doherty, R.M., Wild, O., Shindell, D.T., Zeng, G., MacKenzie, I.A., Collins, W.J., Fiore, A.M., Stevenson, D.S, Dentener, F.J., Schultz, M.G., Hess, P., Derwent, R.G., \& Keating,

T.J. (2013). Impacts of climate change on surface ozone and intercontinental ozone pollution: a multi-model study. Journal of Geophysical Research, 118(9), 3744 - 3763. https://doi.org/10.1002/ igrd.50266

Environmental Protection Agency (EPA). (2017a). Health and environmental effects of particulate matter (PM). EPA. Retrieved November 12, 2017, from: https://www. epa.gov/pm-pollution/health-andenvironmental-effects-particulate-matter-pm

EPA. (2017b). Ozone basics. EPA. Retrieved November 13, 2017, from https://www. epa.gov/ozone-pollution/ozonebasics\#what where how

EPA. (2017c). Nitrogen dioxide $\left(\mathrm{NO}_{2}\right)$ pollution. EPA. Retrieved November 18, 2017, from https://www.epa.gov/ no2-pollution/basic-information-aboutno2\#What is NO2

EPA. (2017d). Sulfur dioxide $\left(\mathrm{SO}_{2}\right)$ pollution. 
EPA. Retrieved on November 18, 2017, from https://www.epa.gov/so2-pollution/ sulfur-dioxide-basics\#what is so 2

EPA. (2011). Air quality guidelines for nitrogen dioxide. EPA Office of Air and Radiation. Retrieved November 29, 2017, from https://www3.epa.gov/airnow/no2.pdf

European Environmental Agency. (n.d.). $\mu \mathrm{g} /$ m3. European Environmental Agency. Retrieved July 6, 2020, from http://www. eea.europa.eu/maps/ozone/resources/ glossary/g-m3

European Environmental Agency. (2012). Particulate matter from natural sources and related reporting under the $E U$ air quality directive in 2008 and 2009. https://www. eea.europa.eu/publications/particulatematter-from-natural-sources

Grote, R., Samson, R., Alonso, R., Amorim, J., Carlnanos, P., Churkina, G., Fares, S., Thiec, D., Niinemets, U., Mikkelsen, T., Paoletti, E., Tiwary, A., and Calfapietra, C. (2016). Functional traits of urban trees: air pollution mitigation potential. Frontiers in Ecology and the Environment, 14(10), 543-550. https:// doi.org/10.1002/fee.1426

Irga, P.J., Burchett, M.D., \& Torpy, F.R. (2015).

Does urban forestry have a quantitative effect on ambient air quality in an urban environment? Atmospheric Environment, 120, 173-181. https://doi.org/10.1016/i. atmosenv.2015.08.050

Jacob, D. J., \& D. A. Winner. (2009). Effect of climate change on air quality. Atmospheric Environment, 43(1), 51-63. https://doi. org/10.1016/i.atmosenv.2008.09.051 Jarvis, D.J., Adamkiewicz, G., Heroux, M.E, Rapp, R., \& Kelly, F. J. (2010). Nitrogen dioxide. In WHO guidelines for indoor air quality: selected pollutants (pp.201-248). Geneva: World Health Organization.

Jerrett, M., Burnett, R. T., Pope, C. A., Ito, K., Thurston, G., Krewski, D., \& Thun, M. (2009). Long-term ozone exposure and mortality. The New England Journal of Medicine, 360(11), 1085-1095. https:// doi.org/10.1056/NEJMoa0803894
Liu, H., Liu, S., Xue, B., Lv, Z., Zhihang M., Yang, X., Xue, T., Yu, Q., \& He, K. (2017). Ground level ozone pollution and its health impacts in China. Atmospheric Environment, 173, 223-230. https://doi.org/10.1016/i. atmosenv.2017.11.014

Nowak, D.J., Hirabayashi, S., Bodine, A., \& Hoehn, R. (2013). Modeled PM 2.5 removal by trees in ten U.S. cities and associated health effects. Environmental Pollution, 178, 395-402. http://doi.org/10.1016/i. envpol.2013.03.050

Pugh, T., MacKenzie, A., Whyatt, J., \& Hewitt, C. (2012). Effectiveness of green infrastructure for improvement of air quality in urban street canyons. Environmental Science \& Technology, 46(14), 7692-7699. https:// doi.org/10.1021/es300826w

Richie, H., \& Roser, M. (2017). Air Pollution. Our World In Data. https:// ourworldindata.org/air-pollution/

Selmi, W., Weber, C., Rivière, E., Blond, N., Mehdi, L., \& Nowak, D. (2016). Air pollution removal by trees in public green spaces in Strasbourg city, France. Urban Forestry \& Urban Greening, 17, 192-201. http://doi. org/10.1016/i.ufug.2016.04.010

Shaneyfelt, K., Anderson, A., Kumar, P., \& Hunt, W. (2017). Air quality considerations for stormwater green street design. Environmental Pollution, 231, 768-778. http://doi.org/10.1016/i. envpol.2017.08.081

Simon, H., Reff, A., Wells, B., Xing, J., \& Frank, N. (2015). Ozone trends across the United States over a period of decreasing NOx and VOC emissions. Environment, Science, and Technology, 49, 186-195. https://doi. org/10.1021/es504514z

Strosnider, H., Kennedy, C., Monti, M., \& Yip, F. (2017). Rural and urban differences in air quality, 2008-2012, and community drinking water quality, 2010-2015 - United States. Morbidity and Mortality Weekly Report Surveillance Summaries, 66(13), 1-10. http://doi.org/10.15585/mmwr. ss6613al 
Tiwary, A., Sinnett, D., Peachey, C., Chalabi, Z., Vardoulakis, S., Fletcher, F., Leonardi, G., Grundy, C., Azapagic, A., \& Hutchings, T. (2009). An integrated tool to assess the role of new planting in $\mathrm{PM}_{10}$ capture and the human health benefits: A case study in London. Environmental Pollution, 157(10), 2645-2653. http://doi.org/10.1016/i. envpol.2009.05.005

Weinhold B. (2008) Ozone nation: EPA standard panned by the people. Environmental Health Perspectives, 116(7), 302-305. https://doi.org/10.1289/ ehp.116-a302

West Michigan Clean Air Coalition, (2017). Factors that contribute to the formation of ozone and particulate matter. West Michigan Clean Air Action. Retrieved November 15, 2017, from http://www. wmcac.org/airquality/factors.html Weuve, J., Puett, R.C., Schwartz, J., Yanosky, J.D., Laden, F., \& Grodstein, F. (2012). Exposure To particulate air pollution and cognitive decline in older women. Archives of Internal Medicine, 172, 219-227. https:// doi.org/10.1001/archinternmed.2011.683 World Health Organisation (WHO). (2003). Health aspects of air pollution with particulate matter, ozone, and nitrogen dioxide. https://apps.who.int/iris/ handle/10665/107478

World Health Organisation (WHO). (2005). Air quality guidelines for particulate matter, ozone, nitrogen dioxide, and sulfur dioxide: global update 2005: summary of risk assessment. https://apps.who.int/iris/ handle/10665/69477

World Health Organisation (WHO). (2013). Health effects of particulate matter: policy implications for countries in Eastern Europe, Caucasus, and central Asia. https:// www.euro.who.int/en/health-topics/ environment-and-health/air-quality/ publications $/ 2013 /$ health-effects-ofparticulate-matter.-policy-implications-forcountries-in-eastern-europe,-caucasus-andcentral-asia-2013
World Health Organisation (WHO). (2016). Ambient air pollution: a global assessment of exposure and burden of disease. https:// www.who.int/phe/publications/airpollution-global-assessment/en/

Xing, Y., Xu, Y., Shi, M., \& Lian, Y. (2016). The impact of $\mathrm{PM}_{2.5}$ on the human respiratory system. Journal of Thoracic Disease, 8(1), 69-74. https://doi.org/10.3978/i. issn.2072-1439.2016.01.19

Zupancic, T., Westmacott, C., and Bulthuis, M. (2015). The impact of green space on heat and air pollution in urban communities: A meta-narrative systematic review. David Suzuki Foundation. Retrieved from https://davidsuzuki.org/wp-content/ uploads/2017/09/impact-green-spaceheat-air-pollution-urban-communities.pdf 


\section{References}

Brenner, N. (2004). New State Spaces: Urban Governance and the rescaling of Statehood. Oxford: Oxford University Press.

Carmona, M., De Magalhães, C. \& Edwards, M. (2002). Stakeholder views on value and urban design. Journal of Urban Design, 7(2), 145-169. doi:10.1080/1357480022 000012212

Cilliers, E. J. \& Timmermans, W. (2014). The importance of creative participatory planning in the public placemaking process. Environment and Planning B: Urban Analytics and City Science, 41(3), 413-429. doi:10.1068/b39098

City of Edmonton. (n.d.). Experience Jasper Avenue. Retrieved from https://www. edmonton.ca/projects_plans/experiencejasper-avenue.aspx

City of Edmonton. (2017, July). Imagine Jasper Avenue / Experience Jasper Avenue: Project journey. Retrieved from https://www.edmonton.ca/documents/ ExperienceJasperAve_Journey_July2017. pdf

Elliott, D. L. (Eds.). (2008). A Better Way to Zone: Ten Principles to Create More Livable Cities. Washington, DC: Island Press. Retrieved from https://books.google. $\mathrm{ca} /$ books?hl=en\&lr=\&id=|F3QwhFqGYC\&oi=fnd\&pg $=P R 5 \& d q=a$ + better+way+to+zone\&ots $=7 q 813 r$ y49\&sig=SOEoc_iUI_

Xsx8kdxnFVQyVxqLO\#v=one page $\& q=a \% 20$ better $\% 20$ way $\% 20$ to $\% 20$ zone $\& f=f a l s e$

Fontana, A. \& Pasquino, P. (1991) 'Truth and power', an interview with Foucault, in P. Rainbow (Ed.) The Foucault Reader. London: Penguin.

Foucault, M. (1988). The History of Sexuality. First Vintage Books ed. New York: Vintage Books. Retrieved from http://www.michelfoucault.com/dulwich/power.pdf
Friedmann, J. (2010). Place and placemaking in cities: A global perspective. Planning Theory \& Practice, 11 (2), 149-165. doi: $10.1080 / 14649351003759573$

Project for Public Spaces (PPS). (2014, March 19). Streets as places: How transportation can create a sense of community. Retrieved from https://www.pps.org/reference/ streets-as-places-how-transportation-cancreate-a-sense-of-community/

PPS. (2009a, December 31). About. Retrieved from https://www.pps.org/about/

PPS. (2009b, December 31 ) Streets as places: Streets are for... everything. Retrieved from https://www.pps.org/reference/streets-asplaces/

PPS. (2009c, December 31). What is placemaking? Retrieved from https://www. pps.org/reference/what_is_placemaking/

Richardson, T. (1995). Foucauldian discourse: Power and truth in urban and regional policy making. European Planning Studies, 4(3), 279-292. doi:10.1080/09654319608720346

Seamon, D. (2012). 'A jumping, joyous urban jumble': Jane Jacobs' Death and Life of Great American Cities as a phenomenology of urban place. The Journal of Space Syntax, 3(1), 139-149. Retrieved from http://joss.bartlett.ucl.ac.uk/journal/index. $\mathrm{php} /$ joss/article/view/121/pdf

Van Assche, K., Beunen, R., Duineveld, M., \& de Jong, H. (2013). Co-evolutions of planning and design: Risks and benefits of design perspectives in planning systems. Planning Theory, 12(2), 177-198. doi:10.1177/1473095212456771

Wagner, A. (2011). French urban space management: A visual semiotic approach behind power and control. International Journal for the Semiotics of Law, 24(2), 227-241. doi:10.1007/s 11196-010-9206-5 